\title{
PODER Y POSTMODERNIDAD
}

Julián Meza*

\begin{abstract}
$\mathbf{P}_{\text {ara hablar de la postmodernidad y }}$ de las figuras del poder que actúan y prevalecen en ella es conveniente hablar antes -una vez más, por supuesto- de la modernidad, aun cuando parezca un tema envejecido, en desuso y casi herrumbrado. No creo poder añadir gran cosa al respecto, pero sí puedo recordar algunos conceptos que, para nuestra desgracia, se han olvidado, porque vivimos abrumados de abundantes informaciones insignificantes, numerosos conocimientos trillados y lugares comunes que recuerdan los prejuicios puestos al desnudo por Flaubert cuando habla del burgués filisteo y de su imbecilidad característica.

Aunque alguna vez estudié filosofía, y me licencié (más como licencioso que como docto en la materia), no abordaré el tema desde esa perspectiva, que hoy me parece poco menos que ilusoria -prefiero decir ilusoria a utópica. Tampoco lo haré desde el punto de vista del científico social o del politólogo que no soy, y que no aspiro a ser, para mi buena suerte y, sobre todo, para fortuna del lector. Como escritor, me basta con apoyarme en la opinión de ese extraordinario poeta de la modernidad llamado Charles Baudelaire.

Baudelaire es, ante todo, el poeta de la modernidad. Es también, al mismo tiempo, por paradójico que esto pudiera parecer, el primer gran crítico de la modernidad. En su obra da cuenta de la existencia de este
\end{abstract}

* Instituto Tecnológico Autónomo de México. 


\section{JULIÁN MEZA}

supuesto período histórico y, a la vez, hace su crítica de la manera más radical posible, por supuesto.

En un ensayo titulado "Del heroísmo de la vida moderna", que fue escrito con motivo del Salón de la pintura de 1846, Baudelaire nos dice: "Mucha gente atribuye la decadencia de la pintura a la decadencia de las costumbres. Este prejuicio de taller, que ha circulado entre el público, es una mala excusa de los artistas, que estaban interesados en representar sin cesar el pasado, y de esto la pereza ha sacado provecho."

A continuación añade, a manera de conclusión: "Es verdad que la gran tradición se perdió, y que la nueva todavía no está hecha."

Haciendo una paráfrasis de este escrito de Baudelaire quiero decir que hoy mucha gente atribuye, sin sentido, la decadencia del pensamiento y de la política a la decadencia de las costumbres (o a la pérdida de los valores tradicionales), que no es a fin de cuentas sino una verdad de perogrullo, o un pretexto para aquellos que, autoproclamándose voceros del porvenir (radiante o apocalíptico), sólo añoran el pasado (lejano o inmediato, feudal o soviético), y se conforman con vivir apoltronados en el presente (globalizador y de bloques fraudulentamente económicos y financieros). Y así ocurre porque, en mi opinión,

130 la gran tradición intelectual, artística y política parece haber desaparecido (ya no hay socialistas utópicos ni supuestamente científicos, ya no hay vanguardias ni existencialismos, ya no hay Valery, Camus, Sartre, Aron y Foucault). Es cierto que siguen vivos Castoriadis, Lefort, Morin, Furet, Chomsky y Hobsbawn, pero todavía no ha nacido una nueva tradición. A1 igual que hace más de un siglo, vivimos en la tierra de nadie o de "nunca jamás", y de aquí el recurso, a mi juicio falaz, que nos invita a hablar de postmodernidad en ausencia de ideas, proyectos, sueños e imaginación.

En el mismo ensayo dice Baudelaire más adelante: "(...) la mayor parte de los artistas que han abordado los temas modernos se han contentado con los temas públicos y oficiales, con nuestras víctimas y nuestro heroísmo político, y lo hacen a regañadientes, porque son mandados por el gobierno que les paga. Y, sin embargo, hay temas privados, que son heroicos de manera muy distinta". 
Otra vez parafraseando a Baudelaire quiero decir que nuestros intelectuales se han contentado con temas públicos y oficiales: el Estado, el gobierno, el sistema político, el partido oficial, los partidos de oposición, la realpolitik, las ideologías, la enajenación, el porvenir radiante o los medios de comunicación; con sus repetidas y aburridas quejas; con sus pírricas victorias, pactadas cada fin de semana; con sus mártires prefabricados (en Chiapas) o con su heroísmo ramplón (en cada elección). Pero no creo que lo hagan a regañadientes, porque con demasiada frecuencia es el gobierno el que los manda y el que les paga, y a menudo les paga muy bien -independientemente de que se trate de gacetilleros incondicionales, de bufones de toda laya, de guerrilleros encapuchados, de feministas sin sostén, de ecologistas con sed de poder ambiental, de indigenistas disfrazados de fray Bartolomé de las Casas, de columnistas políticos a sueldo, o de cronistas de sociales que, desde su residencia en Las Lomas salmodian a los pobres, y aun a los miserables. En cambio, al igual que algunos de los contemporáneos de Baudelaire, nuestros intelectuales han descuidado el heroísmo privado de temas tales como la reflexión, la soledad, la crítica, el sueño, la creatividad, la tolerancia, la imaginación o el humor. La vida mexicana es fecunda en temas poéticos y maravillosos, que podrían ser fácil pasto del imaginario. Aun cuando nos cueste trabajo creerlo, lo maravilloso nos envuelve y podría saciar nuestra sed de ilusiones, pero no lo vemos porque carecemos de los ojos de Joyce, de Kafka o de Proust. Somos incapaces de observar el mundo como es y, en cambio, lo vemos como quisiéramos que fuera, o peor aún, como creemos que es.

En otro texto, realmente extraordinario, escrito a propósito del Salón de la pintura de 1859, y que precisamente lleva par título "La modernidad", Baudelaire escribe: "Así va él (el artista), corre, busca. ¿Qué busca? Tal y como lo he dibujado, seguramente este hombre, este solitario dotado de una imaginación activa, que viaja siempre a través de el gran desierto de los hombres, tiene una meta más elevada que la del simple flâneur (el dandy que pasea sin meta), un objetivo más general, distinto del placer fugitivo de la circunstancia. Busca algo que se nos 


\section{JULIÁN MEZA}

permitirá llamar la modernidad, pues no se presenta mejor palabra para expresar la idea en cuestión. Se trata, para él, de extraer de la moda lo que puede contener de poético en lo histórico, de extraer lo eterno de lo transitorio."

E1 artista contemporáneo de Baudelaire buscaba con lógicas y comprensibles prisas (porque aún era prisionero del asombro y de la extrañeza), quería dar un sentido a su obra por encima de las circunstancias, y a fin de cuentas en muchos casos lo logró, porque estaba dotado de un recurso: la imaginación activa, que le permitió atravesar el gran desierto de los hombres. Hoy, cuando el desierto crece y lo diverso decrece la situación es totalmente diferente porque la imaginación activa parece habernos abandonado. Así lo demuestra la ausencia de metas mucho más elevadas que las de los tristes y soporíferos medios de comunicación, empantanados en su verborrea y en sus imágenes gastadas de tan piadosas, en la falta de objetivos en general y, peor aún, en la complicidad con el ascenso de la insignificancia del que habla Castoriadis cuando se refiere a nuestra cotidiana complacencia con las groseras banalidades del progreso.

Vivimos prisioneros de nuestra circunstancia, de la moda, de lo tran-

132 sitorio, del instante instaurado por la modernidad, en lugar de hacer lo que hizo el artista moderno que se convirtió en crítico de la modernidad: extraer lo poético de lo histórico, lo eterno de lo transitorio, lo trascendente de lo cotidiano, y consumirnos en el instante. Sin embargo, pretendemos estar más allá de la modernidad, instalados a nuestras anchas en la postmodernidad arquitectónica, ambientalista, urbanística, decorativa y filosófica.

"La modernidad es - puntualiza más adelante Baudelaire en el mismo ensayo- lo transitorio, lo fugitivo, lo contingente, la mitad del arte, cuya otra mitad es lo eterno y lo inmutable. Hubo una modernidad - precisa-para cada pintor antiguo; la mayor parte de los hermosos retratos que nos quedan de épocas pasadas están revestidos - enfatiza-con los ropajes de su época. Son perfectamente armónicos porque el vestido, el peinado y aun el gesto, la mirada y la sonrisa (cada época tiene su porte, su mirada y su sonrisa) forman un todo de una completa vitali- 
dad. Este elemento transitorio, fugitivo, cuyas metamorfosis son tan frecuentes, no tenemos derecho a despreciarlo o a pasarlo par alto. Al suprimirlo caemos forzosamente en el vacío de una belleza abstracta e indefinible, como la de la única mujer antes del primer pecado. Si sustituimos el vestido de una época con otro, impuesto necesariamente, provocamos un contrasentido que no puede tener excusa sino debido a una bufonada querida por la moda."

En resumen, la característica fundamental de la modernidad es lo fugaz, lo transitorio. En otras palabras: es el instante. Esto constituye la mitad del arte, o de la reflexión. La otra mitad es, y esto es en definitiva lo más importante, la capacidad del artista, o del intelectual, para extraer lo eterno de lo transitorio, cuando tiene capacidad para el asombro, para la observación, y carece de compromisos con los poderes establecidos, o a punto de establecerse como meras piezas de recambio o simples soluciones de continuidad.

Todas las épocas han tenido su modernidad, su instante; y lo que ha trascendido de esas modernidades ha sido la capacidad del artista, el poeta, el intelectual para captar sus diferentes rasgos, ropajes y características, y extraer de ellas lo trascendente. Esa fue la virtud, antaño, de Homero, Sócrates, Bocaccio, Dante o Maquiavelo; y, en tiempos más recientes, de Flaubert, Rimbaud, Monet, Nietzsche, el mismo Baudelaire, Picasso, Céline, Buñuel o Borges.

En las obras de todos estos grandes creadores no hay los ropajes ni los gestos de los excelsos artistas pretéritos, sino los de sus propias épocas. En cambio, la postmodernidad me parece que es, en el mejor de los casos, una bufonada impuesta por la moda y el circo de las circunstancias. ¿O qué otra cosa es esa pretensión de querer haber dejado atrás la modernidad al refugiarse en el interior de un gran decorado art nouveau $\mathrm{o}$ art déco, e instalarse en una sospechosa vuelta a la feudalidad que no deja de ser una falsa puerta de escape a la modernidad? Los románticos nunca fueron tan necios y pretenciosos como nuestros postmodernos, dado que volvieron a la Grecia clásica conscientes de que su retorno era sólo un viaje al pasado. Ése fue el magnífico caso de Hölderling o el de Novalis. 


\section{JULIÁN MEZA}

Tal vez asistimos al final de los tiempos modernos. Pero este final forma parte de un prolongado proceso que se inició con la crítica del artista mediocre que inauguró la modernidad, que continuó con Baudelaire, que siguió su camino con Nietzsche, Husserl y Foucault, entre otros, y que, sospecho, aún está lejos de haber desembocado en el umbral de otra época. Roma no se acabó con el poder del emperador Constantino y, para nuestra desgracia, los totalitarismos de este siglo están lejos de haber sido definitivamente conjurados, como lo demuestra el actual ascenso de la xenofobia y el racismo en todo el mundo.

En política la permanencia de la modernidad me parece más que evidente. Proseguimos en la búsqueda de la democracia iniciada en los albores de los tiempos modernos, pero sin haber añadido un ápice a la Declaración universal de los derechos del hombre y del ciudadano, que aún no adquieren del todo carta de ciudadanía en México. La reflexión sobre el poder no sólo no ha ido más allá de la modernidad, sino que repite infatigablemente sus conceptos y sus prácticas más desgastadas: los partidos políticos (que ya no son clubes revolucionarios, ni logias masónicas, y ni siquiera círculos de lecturas), las elec-

134 ciones (que en el mejor de los casos se han convertido en un circo o en una feria republicana en California), la competitividad ( $i$ siempre tan incompetente!), la economía de mercado (puesta a raya por el proteccionismo), el individualismo (disminuido por él mismo) y lo políticamente correcto, que nunca dejó de ser incorrecto desde los tiempos de Cervantes, Shakespeare y Montaigne.

Nuestros tecnocráticos, rectos y correctos economistas hablan de globalización como si se tratara de algo realmente nuevo, cuando ese proceso lo iniciaron Inglaterra y Francia con sus respectivas revoluciones hace más de doscientos años. Además, nuestros economistas parecen haber olvidado la nefasta experiencia de la pretensión globalizadora de los soviéticos (la internacional comunista y el internacionalismo proletario, que no impidieron llamar a Stalin rústico georgiano, y que tampoco evitaron que los rusos y los polacos trataran a los asiáticos, a los africanos y a los cubanos como ciudadanos de tercera clase) y la 
división del mundo en bloques políticos (comunismo y capitalismo), que ahora pretenden sustituirla, sin éxito, con la idea de los bloques económicos, que no son ni la supuesta unidad europea-que no deja de ser un proyecto, permanentemente amenazado por el sometimiento de Inglaterra a los USA y la riñas comerciales entre sus diferentes socios, que sólo conjuran la amenaza norteamericana gracias a la posesión de la bomba-; ni la unidad asiática, siempre relativa (los japoneses odian a los coreanos tanto como los norteamericanos a los europeos) y que no incluye a la China poseedora de la bomba; ni menos aún el Tratado de Libre Comercio de América del Norte, que no pasa de ser un chiste -de mal gusto, por cierto-, al menos entre los ilegales latinoamericanos en USA, las clases medias venidas a menos y los propietarios de las pequeñas y medianas empresas mexicanas que fueron arrojadas al libre mercado carentes de experiencia y de otras supuestas ventajas comparativas.

África sobrevive en una época muy anterior a la modernidad (en el mejor de los casos es nómada e infelizmente recolectora) y el centro de la ex-potencia soviética (Rusia) no es menos miserable y triste que un país que, como México, se halla permanentemente entregado a resolver problemas elementales causados por mafias políticas y cárteles postmodernos.

Frente a este desolador panorama numerosos intelectuales disertan acerca de la postmodernidad sin avanzar una sola idea, sin tener en mente proyectos de vida diferentes, consumidos por la moda individualista y misantrópica, que no excluye la xenofobia y el racismo, y que no cesa de reiterarse con toda su estúpida monotonía y sus negros horrores desde hace más de cien años.

No quiero concluir sin añadir otra frase de Baudelaire, que resume en buena medida su época y, por supuesto, la nuestra: "Para la mayor parte de nosotros, sobre todo para los negociantes - a los ojos de los cuales la naturaleza no existe, excepto en sus relaciones de utilidad con sus negocios- lo fantástico real de la vida está singularmente debilitado." 


\section{JULIÁN MEZA}

Y de aquí que las figuras del poder en los tiempos que corren no sean muy diferentes a aquéllas que se impusieron desde el inicio de los tiempos modernos: la prepotencia, el autoritarismo, la avidez, el abuso, el individualismo propio del burgués filisteo, y el dinero ( $\sin$ incluir el control de las modernas tecnologías, que son, tan sólo, una prolongación de las del pasado inmediato). Para colmo, estas figuras del poder ahora no se ven asediadas por el imaginario o por una sola fantasía vital.

Como decía antes: el desierto (el poder corrosivo de la sociedad moderna y su bienaventurado dinero) crece y la diversidad (el poder de la imaginación y la inteligencia crítica) decrece, y nos engañamos cuando pretendemos haber dejado atrás el triste páramo de la modernidad y las figuras del poder asociadas con ella, para adentrarnos victoriosa (o derrotistamente) en una inexplicada e inexplicable (por inexistente) postmodernidad. Como dice Michel Foucault al iniciar el primer volumen de su Historia de la sexualidad: "Nosotros, victorianos."

Esta frase no es la expresión de un pensamiento débil (como lo quisiera Vattimo), o de un cuento para niños (como lo quisieran Baudrillard y secuaces), sino la constancia de una simple realidad que, de tan obvia, parece casi invisible. A mi juicio los postmodernos son, en el mejor de los casos, tristes victorianos que todavía hablan de represión, de enajenación y de censura porque son incapaces de asociar su imaginario con el de creadores y críticos como el marqués de Sade, Flaubert, Baudelaire, Mallarmé, Buñuel, Céline, Passolini o Borges.

Estoy convencido de que los postmodernos son, en el mejor de los casos, émulos de ese patético funambulista llamado Dalí, que ciertamente acompañó a Buñuel en la aventura de El perro andaluz y de La edad de oro, pero que acabó patéticamente asociado con Francisco Franco y su pudibunda corte de los milagros en una pseudoaristocrática y feudal cruzada.

Después del catastrófico intento de modernización salinista (que hizo realidad uno de los sueños de Marx, dada que produjo la extinción de las clases medias), sin lugar a dudas Zedillo debe ser, por lo menos para los bienaventurados postmodernos, el adalid de la época 


\section{PODER Y POSTMODERNIDAD}

que dejó atrás la aventura africana y pastoril del tercermundismo, aun cuando hoy la postmodernidad se presente en cueros art nouveau o en harapos art déco, porque éste es el único símbolo existente del bienestar para toda la familia -que incluye sobre todo a los hijos de las amorosas familias que se divierten, disfrazados de payasos, en todos los semáforos de la gran ciudad, forjada a fuerza de asfixiantes imecas y de degolladoras udis que no ocultan su marca civilizadora a la mexicana $o$, en otras palabras, los símbolos del poder a la manera charra, fidelista, septembrina, revolucionaria, nacionalista, guadalupana, neoclásica, priísta, panista, perredista y globalizadora. Y que Dios nos proteja, porque no estamos confesados, ni menos aún circuncidados. 